\title{
O MODELO PEDAGÓGICO DA UNIVERSIDADE ABERTA DE PORTUGAL: APRENDER ONLINE NO CURSO DE EDUCAÇÃO
}

\author{
Lúcia Amante* \\ Pedro Cabral**
}

\section{RESUMO}

Apresentamos neste texto o percurso seguido ao longo de uma Unidade Curricular, integrada no $2^{\circ}$ ano da graduação em Educação lecionada em regime online na Universidade Aberta (UAb), a universidade pública de educação a distância de Portugal. Nesta Unidade Curricular os estudantes são chamados a conceber e desenvolver um pequeno projeto de investigação que visa a iniciação ao desenvolvimento de competências base de pesquisa em contextos educacionais. Tomando como base o modelo pedagógico virtual da UAb, a Unidade Curricular foi planeada tendo em conta a sua especificidade que apela à prática da investigação no terreno. Pretende-se apresentar o design curricular adotado, designadamente como foi alicerçado o percurso de aprendizagem na sala de aula virtual e como foi pensada a interação entre estudantes de modo a promover a reflexão e partilha de saberes entre o grupo. A avaliação proposta foi pensada de modo a testar o desenvolvimento efetivo das competências visadas, mas assumindo expressamente uma dimensão formadora, ou seja, constituindo-se como parte integrante do ato pedagógico e do processo de aprendizagem. À reflexão dos docentes sobre o desenvolvimento dos trabalhos na Unidade Curricular, enquanto observadores participantes, junta-se a análise da perspectiva dos estudantes, avaliada por questionário, aplicado às duas turmas do curso.

Palavras-chave: Modelo pedagógico. Aprendizagem online. Design instrucional. Avaliação.

\section{ABSTRACT \\ THE PEDAGOGICAL MODEL OF THE OPEN UNIVERSITY OF PORTUGAL: LEARNING ONLINE IN AN EDUCATION COURSE}

We present, in this paper, the steps of an online course, from a graduation in Education, at the public Open University (UAB) of Portugal. In this course, students must design and develop a small research project, which aims the development of basic research skills in educational contexts. Based on the virtual pedagogical model of $U A B$, the course was planned taking into account the specificity of the field research practice. We present the curriculum design adopted in the virtual classroom, designed to promote interaction among students in order to promote reflection and shared knowledge within

*Doutora em Educação pela Universidade Aberta - Portugal. Professora Auxiliar nesta Universidade. Investigadora no Laboratório de Educação a Distância e Elearning. Rua da Escola Politécnica, 141-147, 1269-001 Lisboa. lucia.amante@uab.pt

** Mestre em Supervisão Pedagógica pela Universidade Aberta - Portugal. Bolsista do Instituto de Educação da Universidade de Lisboa. Doutorando em Educação da Universidade Aberta (Laboratório de Educação a Distância e Elearning). Rua da Escola Politécnica, 141-147, 1269-001 Lisboa.pedro.manuel.cabral@gmail.com 
the group. The assessment was designed to test the effective development of targeted skills but also assuming a formative dimension and becoming an integral part of the pedagogical act and of the learning process. We analyze the considerations of the teachers as participants and observers as well as the students' perspective assessed by a survey answered by the students from both classes of the course.

Keywords: Pedagogical model; online learning; instructional design, assessment.

\section{O Modelo Pedagógico da Universidade Aberta}

A Universidade Aberta de Portugal tem sofrido, nos últimos anos, profundas mudanças, inscritas no âmbito do seu plano estratégico de inovação. Tratando-se de uma Universidade de ensino a distância, nela se refletiu em particular a necessidade de acompanhar as profundas transformações da sociedade. Se os avanços tecnológicos, e em particular a Internet, têm vindo a promover essas mudanças, oferecendo novas e privilegiadas possibilidades à educação a distância, torna-se, contudo, necessário articular as novas possibilidades tecnológicas com a renovação dos modelos pedagógicos industriais tradicionalmente usados nestes contextos, para fazer frente aos novos desafios que se colocam à educação e à educação a distância em particular.

Com efeito, o espaço europeu de educação superior vem determinar uma maior responsabilização do estudante pelo seu processo de aprendizagem, ao mesmo tempo que exige novos modos de ensinar e aprender, colocando a ênfase na aquisição e desenvolvimento de competências e por isso requerendo novas posturas pedagógicas.

Nesse sentido, desde 2007, os novos cursos da Universidade Aberta, já desenhados de acordo com o tratado de Bolonha, passaram a funcionar tendo por base um modelo pedagógico virtual desenvolvido na própria instituição (PEREIRA et al, 2007). Este novo modelo pedagógico, assenta em quatro grandes linhas de força:

- a aprendizagem centrada no estudante;

- o primado da flexibilidade;

- o primado da interação;

- o princípio da inclusão digital.

A aprendizagem centrada no estudante, na medida em que este é encarado como "indivíduo activo, construtor do seu conhecimento, empenhando- -se e comprometendo-se com o seu processo de aprendizagem e integrado numa comunidade de aprendizagem"(PEREIRA et al, 2007, p. 11).

Assim, as situações de ensino são desenhadas em função do estudante, tendo em vista o desenvolvimento de um conjunto de competências previamente definidas. O planejamento das atividades assume particular relevância, e a aprendizagem realiza-se quer através de estratégias de autoaprendizagem, quer através da interacção entre pares, dando lugar a estratégias de aprendizagem cooperativas e colaborativas.

Nessa perspectiva, altera-se substancialmente o papel do professor, exigindo-se-lhe que atue como facilitador do processo de aprendizagem, levando o estudante a desenvolver capacidades metacognitivas, quer através do desenho de atividades de aprendizagem relevantes, quer disponibilizando recursos, quer organizando a colaboração e estimulando a interação dentro da comunidade de aprendizagem, promovendo a reflexão conjunta.

Quanto ao primado da flexibilidade, advoga a possibilidade de o estudante poder aprender onde e quando quiser, sem constrangimentos de espaço ou de tempo, tendo em consideração o perfil do estudante típico da Universidade Aberta: adulto, com responsabilidades profissionais, familiares e cívicas. Assim, o modelo constitui-se como essencialmente assíncrono, permitindo a não coincidência de espaço e não coincidência de tempo entre os intervenientes envolvidos.

A ênfase nas tecnologias assíncronas possibilita ao estudante gerir efectivamente os seus tempos de acesso online, de pesquisa individual, de estudo e aprofundamento dos temas e/ou de interacção com o professor e os outros estudantes. Por um lado, a possibilidade de o estudante se envolver em discussões e debates sem hora marcada, aumenta a flexibilidade de gestão temporal da aprendizagem. (PEREIRA et al, 2007, p. 12). 
O princípio da interação é também um vetor estruturante desse modelo, salientando-se a importância desta variável habitualmente crítica nos processos tradicionais de aprendizagem a distância.

Se nas primeiras gerações de ensino a distância a interacção era fundamentalmente entendida como interacção estudante-conteúdo e interacção estudante-professor, no modelo aqui explicitado ela alarga-se de forma decisiva à interacção estudante-estudante, através da criação de grupos de discussão no interior de cada turma virtual, implicando o seu planeamento prévio (o desenho instrucional) e estratégias de activação da aprendizagem, de modo a estimular a iniciativa e o envolvimento dos estudantes, bem como a garantir a sua frequência e orientar a natureza do seu trabalho (PEREIRA et al, 2007, p. 13).

Por último, o princípio da inclusão digital "entendida como a facilitação do acesso aos adultos que pretendam frequentar um programa numa instituição superior e não tenham ainda adquirido desenvoltura na utilização das Tecnologias da Informação e Comunicação" (PEREIRA et al, 2007, p. 14).

Entende-se assim que se torna fundamental que a educação de adultos a distância contribua para o desenvolvimento de literacia digital, impulsionando-o a partir da motivação e necessidade do uso das novas ferramentas. Neste sentido, e tendo em conta que o ensino online exige competências específicas por parte do estudante, todos os programas de formação certificados pela Universidade Aberta incluirão um módulo prévio, designado "módulo de ambientação". Este módulo, realizado online, permite aos novos estudantes adquirir essas competências antes da frequência do curso ou programa de formação em que se inscreveram.

São, pois, esses quatro princípios-base que norteiam a organização do ensino, a planificação, a concepção e gestão das atividades de aprendizagem a propor aos estudantes, a tipologia de materiais a desenvolver e a natureza da avaliação das competências desenvolvidas.

No que se refere à sua operacionalização, esse modelo apresenta variantes distintas para o $1^{\circ}$ e $2^{\circ}$ ciclo. Neste texto abordaremos sucintamente as características da variante do $1^{\circ}$ ciclo, dado que é nesse âmbito que se inscreve a experiência que aqui pretendemos relatar.

\section{Os elementos pedagógicos ao nível dos cursos de graduação}

As atividades de aprendizagem decorrem no espaço da turma virtual de cada unidade curricular ao longo de cada semestre, sendo realizadas online com recurso a dispositivos de comunicação. Com base nestes dispositivos são organizados fóruns de dois tipos: fóruns moderados pelos estudantes e fóruns moderados pelo professor. Os fóruns moderados pelos estudantes constituem espaços de trabalho da turma. Neles deverá ter lugar a interação entre pares a propósito da temática em estudo. Os fóruns moderados pelo professor têm como objetivo o esclarecimento de dúvidas e a superação de dificuldades que não tenham sido ultrapassadas através da discussão entre os estudantes. Estes fóruns são abertos em momentos determinados pelo professor. A comunicação é essencialmente assíncrona e, por isso, baseada na escrita.

Na concepção e organização prévia do percurso formativo de ensino e aprendizagem nas unidades curriculares de $1^{\circ}$ ciclo destaca-se um conjunto de elementos-chave que estruturam o processo de aprendizagem: O Plano da Unidade Curricular (PUC), o Plano de Atividades Formativas (PAF) e o Cartão de Aprendizagem (CAP).

O PUC, elaborado pelo professor e apresentado ao estudante no início das atividades, é um documento guia, norteador de todo o processo de aprendizagem. Tem como objetivo ajudar o estudante a conhecer tudo o que se espera dele e, consequentemente, a planejar e organizar o seu trabalho. Nele surgem:
a) As competências a desenvolver;
b) Os temas a estudar;
c) A bibliografia a trabalhar;
d) O que se espera do estudante;
e) O plano de atividades formativas;
f) O calendário que o estudante deve cumprir;
g) Os modos de avaliação;
h) A organização do cartão de aprendizagem do estudante (CAP), com as indicações para a elaboração dos e-fólios adstritos a este elemento.

O Plano de Atividades Formativas (PAF) visa fornecer aos estudantes uma base para trabalhar e 
adquirir objetivos e competências intermédias, no decurso do ciclo de aprendizagem. Estas atividades são disponibilizadas aos estudantes em momentos pré-determinados (definidos no PUC). Podem ter tipologia variada, consoante a natureza das competências a desenvolver, e são acompanhadas de indicações para que o aluno proceda, posteriormente, à sua autoavaliação, permitindo-lhe monitorizar a sua aprendizagem.

O Cartão de Aprendizagem do estudante (CAP) baseia-se na metáfora do "cartão de crédito" e tem como objetivo fundamental valorizar o percurso pessoal de aprendizagem do estudante. Trata-se de um dispositivo eletrônico personalizado que registra os resultados de avaliação contínua do estudante ao longo do seu percurso de aprendizagem na Unidade Curricular (UC), reunindo ainda os comentários qualitativos do professor a essa avaliação.

Ao Cartão de Aprendizagem associa-se o conceito de e-fólio, como instrumento de avaliação contínua. Trata-se de um pequeno documento digital que obedece a instruções fornecidas pelo professor, dependendo a sua natureza da área científica em estudo. Prevê-se que cada estudante possa elaborar, em momentos distintos, dois ou três e-fólios, de acordo com um calendário previamente definido pelo professor da unidade curricular.

Ainda que, no que diz respeito à avaliação, seja dada ao estudante a possibilidade de optar pela realização de um exame final presencial, a filosofia de base desse modelo de $1^{\circ}$ Ciclo pressupõe a realização de avaliação contínua. Esta consubstancia-se, regra geral, na realização de uma componente de avaliação eletrônica referida (e-fólios) e que se associa ao Cartão de Aprendizagem, a que se junta a realização de uma prova presencial (p-fólio).

\section{A unidade curricular Seminário de Investigação}

O Seminário de Investigação corresponde a uma unidade curricular que integra o $2^{\circ}$ ano do plano de estudos de um curso de $1^{\circ}$ ciclo - Licenciatura em Educação.

Nessa unidade curricular pretende-se que o estudante aprenda a delinear e realizar uma pequena investigação no âmbito de temáticas consideradas relevantes, tendo em vista a intervenção educa- cional. Neste âmbito, pretende-se dar início ao desenvolvimento de competências básicas de investigação que permitam ao estudante concretizar o seu projeto.

Nesse sentido, pretende-se que o estudante desenvolva as seguintes competências:

a) Identificar problemas educacionais;

b) Formular uma questão de investigação;

c) Delinear uma metodologia de investigação adequada ao problema/questão em causa;

d) Tratar, analisar e interpretar resultados obtidos;

e) Propor estratégias de intervenção adequadas;

f) Elaborar um relatório de investigação.

\section{O design instrucional da unidade curricular e a metodologia de trabalho}

Tendo como referência diversos autores (GUÀRDIA; SANGRÀ; MAINA, 2007; MATEO, 2006; MATEO; SANGRÀ, 2007; MORGAN; O'REILLY, 1999; SAVERY; DUFFY, 1996), sublinhamos a relevância de considerar no design instrucional das unidades curriculares os fundamentos da avaliação digital propostos por Pereira, Oliveira e Tinoca (2010), e analisados por Gomes, Amante e Oliveira (2012). Neste âmbito destacamos um conjunto de princípios instrucionais que, na nossa perspectiva, emergem como particularmente relevantes e que procuramos ter em consideração ao desenharmos o percurso de aprendizagem da unidade de Seminário de Investigação:

a) a estrutura curricular assente na realização de atividades orientadoras do percurso de aprendizagem;

b) atividades significativas e cognitivamente desafiantes;

c) atividades autênticas e holísticas, no sentido em que deverão assumir significado para os estudantes face à sua realidade;

d) atividades diversificadas mas que requeiram uma resposta concreta, um produto, que evidencie o conhecimento a adquirir ou a competência a desenvolver;

e) situações de aprendizagem em grupo, desencadeadoras de interação e reflexão conjunta entre pares, favorecendo a auto e heterorregulação da aprendizagem; 
f) a consideração da avaliação como um elemento transversal ao conjunto de atividades desenvolvidas ao longo do curso - a avaliação vista como parte integrante do ato pedagógico e do processo de aprendizagem.

Assim, a unidade curricular foi organizada em 5 temáticas: 1. Problema de investigação; 2. Fundamentação teórica da investigação; 3. Metodologia de investigação; 4. Trabalho de campo; 5. Relatório de investigação, abertas sequencialmente ao longo do semestre, no espaço da turma virtual, organizado na plataforma Moodle, que constitui a plataforma de e-learning adotada pela Universidade Aberta, e que a adaptou às características do seu atual modelo pedagógico.

Durante o período dedicado às diferentes temáticas, os estudantes dispunham para além de acesso à bibliografia específica fornecida online, a possibilidade de realizarem atividades formativas propostas pelo professor, dirigidas ao desenvolvimento das competências a adquirir. Simultaneamente, foi disponibilizado em cada temática um fórum de estudantes, sendo estes incentivados a partilhar nesse fórum, com os colegas, os vários aspectos que a abordagem das temáticas os convidava a trabalhar: a formulação das suas questões de investigação (Tema 1), os recursos a utilizar para realizarem o enquadramento teórico das mesmas (Tema 2), a discutir as suas opções metodológicas (Tema 3), ou a colocar outras questões de acordo com o temática em curso. O objetivo destes fóruns visava o desencadear da discussão prévia no seio do grupo, considerando esta interação como promotora da reflexão e da heterorregulação da aprendizagem. Numa fase posterior, depois desta discussão interpares e antes da realização dos e-fólios, eram então disponibilizados os Fóruns moderados pelo Professor, permitindo aprofundar e clarificar essas questões e proporcionando aí orientações que pretendiam levar o aluno a redesenhar ou aperfeiçoar a formulação da sua questão de investigação (Fórum dúvidas 1), a melhor fazer o enquadramento teórico da problemática em estudo, ou a redefinir opções metodológicas (Fórum dúvidas 2), ou a colocar problemas relacionados com o desenvolvimento do trabalho de campo propriamente dito (Fórum dúvidas 3). Salienta-se, contudo, que, nestes fóruns, o docente adotava tipicamente, um comportamento de scaffolding ${ }^{1}$ (WOOD; BRUNER; ROSS, 1976), procurando, sempre que tal se adequava, não dar respostas objetivas, não fornecer a solução aos alunos, realizando, antes, "intervenções estratégicas” (BRUNER, 1978) através de um processo de questionamento progressivo que os leve a encontrar ou a aproximarem-se por si próprios da resposta pretendida.

\section{A avaliação da unidade curricular}

Nessa Unidade, os alunos foram encorajados a optar por avaliação contínua, dado ser esta a modalidade de avaliação que melhor serviria o desenvolvimento das competências a desenvolver, sendo a prova presencial, habitual no modelo pedagógico da UAb para o $1^{\circ}$ Ciclo, substituída por um e-fólio final concluído pelo aluno após o fim da atividade letiva. Esta foi, de fato, a opção da quase totalidade dos alunos (98,25\%, num total de 112 alunos).

Tendo como princípio base a consideração da avaliação como um elemento transversal ao conjunto de atividades de aprendizagem, a avaliação pretendeu constituir-se como parte integrante do ato pedagógico e do processo de aprendizagem (PINTO; SANTOS, 2006). Assim, ao longo do semestre, os alunos eram chamados a desenvolver o seu pequeno projeto de investigação, partindo da sua realidade e dos seus interesses, concretizando-se esse processo em 3 momentos de avaliação, claramente explicitados desde o início: A realização de um $1^{\circ}$ e-fólio, (formulação da questão de investigação, justificação e contextualização da mesma) a ter lugar no final da abordagem da temática 1 ; um $2^{\circ}$ e-fólio no final da temática 3 (Fundamentação teórica da problemática a abordar, definição da metodologia a adotar) e um e-fólio final, após a temática 5, que congregava os dois primeiros (com as reformulações que, entretanto, tivessem sido sugeridas pelo professor, quando da sua correção) e que, complementado com a coleta, tratamento e

\footnotetext{
1 Esse conceito introduzido por Wood, Bruner e Ross (1976) refere-se aos passos dados pelo educador/professor a fim de delimitar uma dada tarefa, procurando levar a o sujeito aprendente a centrar-se nas competências em jogo num dado processo de aquisição. Trata-se de antecipar o desenvolvimento da compreensão da tarefa por parte do sujeito e de agir em consonância com essa antecipação através das designadas "intervenções estratégicas" (BRUNER, 1978).
} 
análise de dados, bem como a sua interpretação, constituía, na prática, o relatório de campo da investigação desenvolvida.

Nos fóruns de dúvidas, anteriores à entrega dos e-fólios, os estudantes tinham oportunidade de apresentar as suas ideias sobre o trabalho a desenvolver no e-fólio, recebendo feedback do professor, a fim de aperfeiçoarem e reformularem, se necessário, as suas propostas. A realização do e-fólio propriamente dito constituía, pois, o ponto de chegada deste processo; este e-fólio depois de avaliado era comentado na sua versão final pelo professor, permitindo, posteriormente, ao estudante redefinir ainda aspectos menos conseguidos (aperfeiçoando o seu projeto), tendo em vista incorporar todas essas alterações quando da realização do e-fólio final que, para além de outras componentes, conjugava os trabalhos até aí realizados. Pretendeu-se apostar na função reguladora da avaliação que percorre todo o processo pedagógico e que funciona assim como um instrumento a serviço da aprendizagem (PINTO; SANTOS, 2006).

\section{Balanço final}

Noventa e três alunos, ou seja $84,6 \%$ dos que optaram por avaliação contínua, chegaram à realização do e-fólio final, registrando-se 17 desistências $(15,5 \%)$. Dos que apresentaram este trabalho final em época normal, 77,3\% obtiveram aprovação na $\mathrm{UC}$, tendo apresentado projetos de natureza muito diversificada, e que, embora constituindo-se como trabalhos de investigação a um nível elementar, revelaram o desenvolvimento de algumas competências básicas fundamentais.

Quadro 1 - Síntese das respostas dos estudantes ao questionário de avaliação sobre o funcionamento da Unidade Curricular "Seminário de Investigação"

\begin{tabular}{|c|c|c|c|}
\hline Itens & $\begin{array}{c}\text { Concordo/ } \\
\text { Concordo } \\
\text { Totalmente }\end{array}$ & $\begin{array}{l}\text { Não Concordo } \\
\text { nem Discordo }\end{array}$ & $\begin{array}{c}\text { Discordo/ } \\
\text { Discordo } \\
\text { Totalmente } \\
\end{array}$ \\
\hline 1. Percebi, desde o início, o funcionamento desta UC & $91,3 \%$ & $8,7 \%$ & - \\
\hline 2. Participei mais do que habitualmente nos fóruns desta UC & $43,5 \%$ & $34,8 \%$ & $21,7 \%$ \\
\hline 3. Sinto que aprendi & $95,7 \%$ & $4,3 \%$ & - \\
\hline 4. Acho que a metodologia de trabalho adotada deve ser alterada & $8,7 \%$ & $13 \%$ & $78,3 \%$ \\
\hline $\begin{array}{l}\text { 5. Senti que as orientações dadas nos fóruns eram insuficientes para } \\
\text { desenvolver o meu projecto }\end{array}$ & $21,7 \%$ & $8,7 \%$ & $69,6 \%$ \\
\hline $\begin{array}{l}\text { 6. Os e-fólios A e B foram muito importantes para realizar com êxito } \\
\text { o e-fólio final }\end{array}$ & $96,1 \%$ & $8,7 \%$ & - \\
\hline $\begin{array}{l}\text { 7. As observações feitas aos e-fólios não me ajudaram a corrigir o que } \\
\text { não estava bem }\end{array}$ & $21,7 \%$ & $8,7 \%$ & $69,6 \%$ \\
\hline 8. Os materiais de estudo fornecidos foram úteis & $78,3 \%$ & $17,4 \%$ & $4,3 \%$ \\
\hline 9. Esta UC foi muito trabalhosa & $73,9 \%$ & $21,7 \%$ & $4,3 \%$ \\
\hline $\begin{array}{l}\text { 10. As orientações dadas pelo professor aos colegas também foram } \\
\text { úteis para a minha aprendizagem }\end{array}$ & $100 \%$ & - & - \\
\hline 11. Acho que os fóruns foram realmente úteis para a aprendizagem & $82,6 \%$ & $13 \%$ & $4,3 \%$ \\
\hline 12. Esperava melhores resultados nesta UC & $52,2 \%$ & $26,1 \%$ & $8,7 \%$ \\
\hline $\begin{array}{l}\text { 13. Sinto que se iniciasse agora outro projeto de investigação, teria } \\
\text { menos dúvidas sobre os passos a dar }\end{array}$ & $95,7 \%$ & $4,3 \%$ & - \\
\hline $\begin{array}{l}\text { 14. Frequentar a UC Investigação Educacional foi importante para } \\
\text { realizar o meu trabalho nesta UC }\end{array}$ & $73,9 \%$ & $21,7 \%$ & $4,3 \%$ \\
\hline 15. O balanço que faço desta UC é, globalmente, positivo & $82,6 \%$ & $8,7 \%$ & $8,7 \%$ \\
\hline
\end{tabular}

Fonte: Elaborado pelos autores deste artigo. 
No que se refere ao balanço realizado pelos estudantes, apresentamos o quadro síntese dos resultados obtidos em resposta ao questionário de avaliação, de resposta anônima, que foi endereçado aos alunos no final do semestre. Este questionário contemplava 15 itens, pedindo-se ao aluno que se pronunciasse sobre cada um deles exprimindo a sua opinião considerando os 5 níveis da escala disponibilizada. Estes níveis foram posteriormente agrupados para tratamento dos dados em 3 categorias (Quadro 1).

Conforme se pode constatar, através da leitura do referido quadro, a avaliação realizada pelos estudantes é, globalmente, muito positiva, destacando-se que 52,2\% dos alunos referiram que esperavam obter melhores resultados nesta UC (Item 12). Ou seja, ainda que para mais da metade dos estudantes os resultados tenham ficado aquém do esperado, estes estudantes fazem, contudo, na generalidade dos itens, uma apreciação bastante favorável sobre a experiência vivenciada na UC, não parecendo que esta avaliação seja influenciada pelas notas obtidas. Assinale-se ainda que mais de $40 \%$ dos estudantes consideram que participaram mais do que habitualmente nos fóruns da Unidade Curricular, ou seja, os níveis de interação conseguidos foram mais significativos, invertendo assim a situação de baixa participação dos estudantes, frequentemente apontada como crítica em grande parte das unidades curriculares que frequentam. Com efeito, $78,3 \%$ dos estudantes consideram que a metodologia de trabalho adotada na UC não deve sofrer alterações, corroborando, assim, a perceção positiva geral evidenciada pelos estudantes sobre o percurso de aprendizagem vivenciado na UC.

$\mathrm{Na}$ perspectiva dos docentes (professor e tutor que orientaram esta UC), há a destacar o elevado grau de interatividade registrado (1335 posts colocados no fóruns, aproximadamente 95 posts por semana), comparativamente à interação genericamente baixa que se registra, habitualmente, nas turmas de graduação. Atribuímos este nível de interação à metodologia de trabalho adotada, designadamente o conhecimento pelos alunos de que as atividades propostas nas diferentes temáticas visavam trabalhar o que lhes viria a ser pedido em termos de avaliação, nos momentos definidos para tal, e o entendimento de que a Unidade era um percurso contínuo a ser acompanhado de perto, como uma escada íngreme que não permite desviar o olhar e a atenção dos degraus, sem que se arrisquem desequilíbrios.

Registramos ainda uma evolução muito positiva em muitos estudantes ao longo da UC, bem como um nível de empenho elevado, considerando também que os resultados finais obtidos na UC se podem considerar muito satisfatórios.

Como aspectos a alterar, destacamos a necessidade de delimitar as grandes áreas temáticas em que os alunos propõem os seus projetos. Com efeito, ainda que se sublinhe a importância de o projeto a desenvolver ter significado para o estudante, relacionando-se com a sua realidade, tornou-se, por vezes, muito difícil abarcar todas as áreas em que os estudantes se propunham realizar a sua investigação, designadamente no que se refere à necessidade de orientar a pesquisa teórica a realizar no âmbito de cada problemática específica apresentada. Por outro lado, parece-nos mais produtivo que os alunos desenvolvam projetos em áreas que no âmbito do seu curso já lhes tenham proporcionado algum aprofundamento teórico, conduzindo-os, assim, a questões de investigação mais pertinentes e fundamentadas. Pensamos, ainda, que esta delimitação temática poderá contribuir para uma interação mais profícua entre os estudantes, dado que os temas em estudo poderão muitas vezes cruzar-se, favorecendo uma maior dinâmica de reflexão conjunta motivada pela partilha de interesses sobre dados temas/questões de investigação.

Também o número de alunos por turma, numa UC dessa natureza, que exige um acompanhamento muito individualizado por parte do professor, requer ser equacionado, de modo a que esse acompanhamento possa efetivamente ter lugar, sem sobrecarregar em demasia os docentes.

Em síntese, avaliamos essa experiência e esse percurso de forma positiva porque, para além dos resultados propriamente ditos e para além das competências concretas desenvolvidas, cremos que a Unidade Curricular permitiu a esses estudantes, em início de formação, a tomada de consciência de que investigar é algo complexo, algo que requer conhecimento teórico, que requer rigor, que requer metodologias específicas e adequadas a cada situação, e que requer saber interligar estes diferentes saberes para que possam desenvolver um trabalho válido. 


\section{REFERÊNCIAS}

BRUNER, J. The role of dialogue in language acquisition. In: SINCLAIR, A.; JARVELLA, R.: LEVELT, W. J. M. (Ed.). The child's conception of language. New York: Springer, 1978. p. 241-256.

GOMES, M. J.; AMANTE, L.; OLIVEIRA, I. Avaliação digital no ensino superior em Portugal: primeiros resultados. Linhas, Universidade do Estado de Santa Catarina, Florianópolis, v. 13, n. 2, p. 10-28, 2012.

GUÀRDIA, L.; SANGRÀ, A.; MAINA, M. Case-based learning in VTLE: an effective strategy for improving learning design. In: BERNATH, U.; SANGRÀ, A. (Ed.). Research on competence development in online distance education and e-learning. Oldenburg: BIS-Verlag der Carl Von Ossietzky Universität Oldenburg, 2007. p. 191-209.

MATEO, J. Claves para el diseño de un nuevo marco conceptual para la medición y evaluación educativa. Revista de Investigación Educativa, v. 24, n. 1, p. 165-186, 2006.

MATEO, J.; SANGRÀ, A. Designing online learning assessment through alternative approaches: facing the concerns. European Journal of Open, Distance and E-Learning, 2007. Disponível em: < http://www.eurodl.org/ materials/contrib/2007/Mateo_Sangra.htm>. Acesso em: 20 out. 2014.

MORGAN, C.; O'REILLY, M. Assessing open and distance learners. Sterling, Va: Stylus Publishing, 1999.

PEREIRA, A. Et al. Modelo pedagógico virtual da Universidade Aberta. Lisboa: Universidade Aberta, 2007.

PEREIRA, A.; OLIVEIRA, I.; TINOCA, L. A cultura de avaliação: que dimensões? In: COSTA, F. Et al. (Ed.). Encontro Internacional TIC e Educação - TICeduca. Lisboa: Universidade de Lisboa, 2010.

PINTO J.; SANTOS, L. Modelos de avalição das aprendizagens. Lisboa: Universidade Aberta, 2006.

SAVERY, J. R.; DUFFY, T. M. Problem based learning: an instructional model and its constructivists framework. In: WILSON, B. (Ed.) Constructivist learning environments: case studies in instructional design. Englewood Clifs, NJ: Educational Technology Publications, 1996. p. 135-148.

WOOD, D.; BRUNER, J.; ROSS, G. The role of tutoring in problem solving. Journal of Child Psychology and Psychiatry, n. 17, p. 89-100, 1976. 